УДК 630*161:634.18(571.51)

СТАБИЛЬНОСТЬ РАЗВИТИЯ РЯБИНЫ ОБЫКНОВЕННОЙ

В УСЛОВИЯХ КРАСНОЯРСКОГО КРАЯ

${ }^{1}$ Слепов А.Н., ${ }^{1}$ Лагунов А.Н., ${ }^{2}$ Коротченко И.С., ${ }^{1}$ Бояринова С.П., ${ }^{3}$ Первышина Г.Г.

${ }^{\prime}$ ФГБОУ ВО «Сибирская пожарно-спасательная академия ГПС МЧС России»,

Железногорск, e-mail: info@sibpsa.ru;

${ }^{2}$ ФББОУ ВО «Красноярский государственный аграрный университет»,

Красноярск, e-mail:kisaspi@mail.ru;

${ }^{3}$ ФГАОУ ВО «Сибирский федеральный университет», Красноярск, е-mail: eva_apple@mail.ru

\begin{abstract}
В статье приведены результаты по стабильности развития листовых пластинок древесных растений, отобранных с различных по степени антропогенной нагрузки территорий Сибири. Растительные объекты исследования сравнивали базовым способом нормировки статистических данных. Дисперсионный анализ позволил выявить, что у листьев рябины обыкновенной обнаруживалась наибольшая асимметрия в ширине листа и расстояния между основаниями первой и второй жилок второго порядка. Следовательно, у листовых пластинок рябины обыкновенной наиболее чувствительными оказались показатели: ширина листа и расстояния между основаниями первой и второй жилок второго порядка. Наибольшие значения интегрального показателя флуктуирующей асимметрии обнаружены у листовых пластинок рябины обыкновенной, взятых на незначительном удалении от предприятия АО «Русал Саяногорский алюминиевый завод» (ИФА $=0,044)$, угольного разреза «Бородинский», Красноярский край $(И Ф А=0,033)$. Показано, что береза повислая обладает более высокой чувствительностью к воздействию антропогенных факторов по сравнению с рябиной обыкновенной. Отмечено, что билатеральный признак ширины левой и правой половинок листовой пластинки более выражен у рябины обыкновенной, возможно, степень варьирования ширины левой и правой половинок листовой пластинки рябины обыкновенной может быть применима при оценке состояния окружающей среды. Показано, что различное состояние урбанизированных сред не определяет снижения стабильности развития популяций рябины обыкновенной, а может указывать на толерантность их к загрязнителям, присутствующим в окружающей природной среде. Это является основанием для рекомендации рябины обыкновенной в системе озеленения территорий с высокой степенью воздействия негативных антропогенных факторов, например санитарно-защитных зон промышленных предприятий.
\end{abstract}

Ключевые слова: рябина обыкновенная, стабильность развития, асимметрия, Красноярский край, антропогенное загрязнение

\title{
DEVELOPMENT STABILITY OF EUROPEAN MOUNTAIN ASH IN CONDITIONS OF KRASNOYARSK TERRITORY (KRAI)
}

${ }^{1}$ Slepov A.N., ${ }^{1}$ Lagunov A.N., ${ }^{2}$ Korotchenko I.S., ${ }^{1}$ Boyarinova S.P., ${ }^{3}$ Pervyshina G.G.

${ }^{1}$ Siberian Fire and Rescue Academy of the State Fire Service of the Emergencies Ministry of Russia, Zheleznogorsk,e-mail: randow2010@yandex.ru;

${ }^{2}$ Krasnoyarsk State Agrarian University, Krasnoyarsk, e-mail: kisaspi@mail.ru; ${ }^{3}$ Siberian Federal University, Krasnoyarsk,e-mail:eva_apple@mail.ru

The article presents the results on the development stability of leaf plates of woody plants selected from territories of the Siberia different by their degree of anthropogenic load. Plant objects in study were compared by the basic method of normalization of statistical data. Dispersion analysis revealed that the leaves of mountain ash were found to have the greatest asymmetry in the width of the leaf and the distance between the bases of the first and second veins of the second order. Consequently, in leaf blades of mountain ash ordinary, the following indicators turned out to be the most sensitive: width of the leaf and the distance between the bases of the first and second veins of the second order. The highest values of the integral indicator of fluctuating asymmetry were found in leaf plates of mountain ash, taken at an insignificant distance from the company AO «Rusal Sayanogorsk aluminum factory» (IFA $=0,044)$, coal mine «Borodino» Krasnoyarsk Krai $($ IFA $=0,033)$. It has been shown that weeping birch has a higher sensitivity to the effects of anthropogenic factors compared to mountain ash. It is noted that the bilateral sign of the lamina width of the left and right halves is more pronounced in mountain ash. Perhaps the degree of variation in the leaf width of the left and right halves of mountain ash may be applicable when assessing the state of the environment. It is shown that a different state of urbanized environments does not determine a decrease in the stability of the development of mountain ash populations, but may indicate their tolerance to pollutants presented in the natural environment. This is the basis for recommending mountain ash in the system of landscaping areas with a high degree of impact of negative anthropogenic factors, such as sanitary protection zones of industrial enterprises.

Keywords: mountain ash, developmental stability, asymmetry, Krasnoyarsk Territory, anthropogenic pollution

В последние годы значительное внимание уделяется оценке качества окружающей среды, особенно урбанизированных территорий, с использованием методов фитоиндикации и, в частности, путем определения флуктуирующей асимметрии (ФА) листовых пластинок растений. Несмотря на то, что наиболее часто при использовании данной методики в качестве модельных объектов выбирают растения с зубчатым краем 
листа [1-3], авторы применяют и растения с цельными краями листьев $[4,5]$, а также растения со сложными листьями [6], листовые пластинки с обрезанных и необрезанных растений тополя бальзамического [7]. В то же время в работах М.В. Козлова с соавторами [8] обращается внимание на то, что получение корректных оценок флуктуирующей асимметрии требует применения трудоемких и достаточно высокоточных измерений, и использование статистических методов обработки полученных результатов. В частности, отмечено, что снижение погрешности измерения возможно при использовании вместо измеряемых счетных признаков, модельных объектов с более крупными листьями и других.

На наш взгляд, перспективным является направление, предложенное в работе В.И. Полонского и И.С. Поляковой [4], связанное с определением наиболее чувствительных показателей билатеральных (измеряемых) признаков при оценке антропогенной нагрузки на городскую среду. Так, авторы установили, что при использовании в качестве модельного объекта листьев сирени венгерской оценка качества окружающей среды может быть произведена на основании установления степени варьирования ширины правой и левой половин листа.

Цель исследования: определить наиболее чувствительные показатели билатеральных признаков листовых пластинок рябины обыкновенной (Sorbus aucuparia) в условиях урбанизированных территорий Красноярского края.

\section{Материалы и методы исследования}

Модельным объектом являлись полносформированные листья рябины обыкновенной, собранные в период 2-9 сентября 2017 г. в ряде урбанизированных территорий Красноярского края (табл. 1).
Выбор территорий был обусловлен следующими причинами:

- опытные участки 1, 3, 5: сбор образцов проводили в условиях городской среды, но в удалении от промышленных предприятий, на расстоянии не менее 50 м от автотрасс;

- опытный участок 2: сбор образцов осуществляли вблизи угольного разреза «Бородинский» Канско-Ачинского угольного бассейна;

- опытный участок 4: условно фоновый (территория Академгородка г. Красноярска);

- опытный участок 6: сбор образцов проводили в незначительном удалении от предприятия АО «Русал Саяногорский алюминиевый завод») (рис. 1).

Поскольку листья рябины обыкновенной сложные, проводили отбор образцов длиной 17-18 см, с 9-11 сидячими широколанцетными зубчатыми по краю листиками. Измерению подвергали один листик с правой стороны листа, длиной 4-5 см. В настоящем исследовании нами была использована широко распространенная методика $[8,9]$, на основании которой для анализа осуществляли отбор не менее 200 шт. листьев на каждом рассматриваемом участке. Данная операция выполнялась с южной и западной стороны кроны (средняя часть) с 5-10 растений. Листья отжимали между слоями фильтровальной бумаги и гербаризировали. Для обмера использовали листовые пластинки, не имеющие механического повреждения или деформации. Измерения выполняли линейкой с точностью 0,5 мм. Измерения проводились пятью участниками, информация о месте сбора листьев была зашифрована. На листовых пластинках осуществляли промеры пяти стандартных [9, 10] метрических билатеральных признаков:

$j_{1}-$ ширины левой и правой половинок листовой пластинки;

$j_{2}-$ расстояния от основания листовой пластинки до конца жилки второго порядка;

Таблица 1

Месторасположение опытных участков

\begin{tabular}{|c|l|c|}
\hline $\begin{array}{c}\text { № опытного } \\
\text { участка }\end{array}$ & \multicolumn{1}{|c|}{ Место произрастания растения } & $\begin{array}{c}\text { Количество листьев, } \\
\text { взятое для измерения }\end{array}$ \\
\hline 1 & г. Боготол, Красноярский край & 226 \\
\hline 2 & Угольный разрез «Бородинский», Красноярский край & 251 \\
\hline 3 & ЗАТО г. Зеленогорск, Красноярский край & 239 \\
\hline 4 & г. Красноярск, Октябрьский район & 256 \\
\hline 5 & г. Красноярск, Свердловский район & 259 \\
\hline 6 & г. Саяногорск, Республика Хакассия & 219 \\
\hline
\end{tabular}




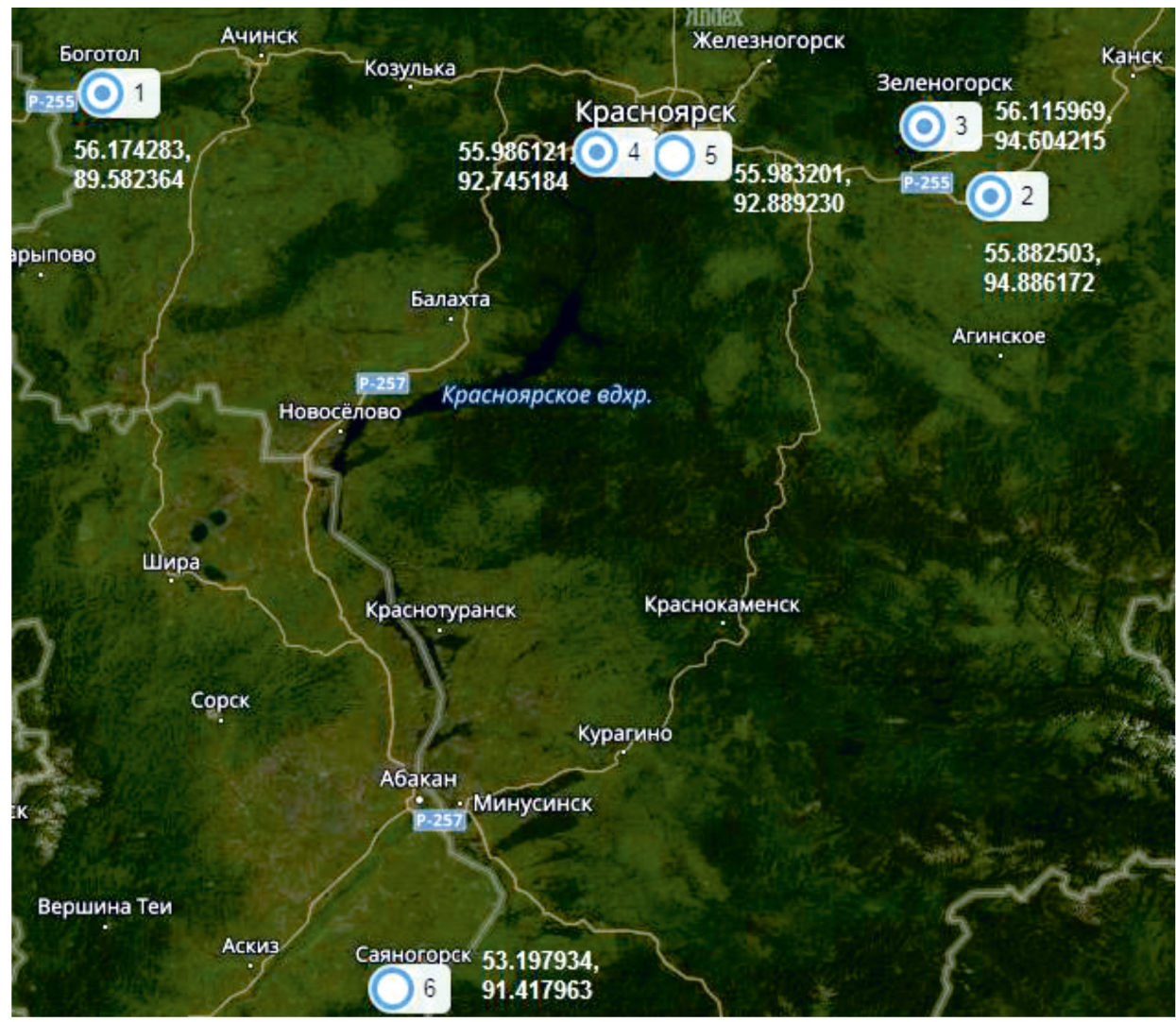

Рис. 1. Карта-схема отбора растительных проб на территории Красноярского края

Таблиша 2

Формулы расчета показателей флуктуирующей асимметрии и интегральных признаков

\begin{tabular}{|c|c|c|c|}
\hline $\begin{array}{c}\text { Одной особи } \\
\text { по одному признаку }\end{array}$ & $\begin{array}{c}\text { Выборки } \\
\text { по одному признаку }\end{array}$ & $\begin{array}{c}\text { Одной особи } \\
\text { по всем признакам }\end{array}$ & Интегральный индекс \\
\hline $\begin{array}{c}f a_{i j}=\left(t_{L i j}-t_{R i j}\right) \\
t_{L i j}=\left(L_{i j}-M L\right) / S L_{j} \\
t R_{i j}=\left(R_{i j}-M R_{j}\right) / S R_{j}\end{array}$ & $f a_{i j}=S_{f a i j}^{2}$ & $f a_{i}=\frac{1}{m} \sum_{j=1}^{m} f a_{i j}$ & $F a=S_{f a i}^{2}$ \\
\hline
\end{tabular}

П р и м еч ан и е. М и $\mathrm{S}$ - средняя арифметическая и стандартное отклонение билатерального признака по всем выборкам, участвующим в сравнении, $S_{f a i j}^{2}-$ дисперсия разности сторон.

$j_{3}-$ расстояния между основаниями первой и второй жилок второго порядка;

$j_{4}-$ расстояния между концами первой и второй жилок второго порядка;

$j_{5}-$ угла между главной жилкой и второй от основания листа жилкой второго порядка.

Ранее А.А. Зориной [11] было установлено, что объекты разного качества можно сравнивать при использовании базового способа нормировки статистических данных, статистическая обработка данных проводилась с его использованием (табл. 2).

\section{Результаты исследования и их обсуждение}

Результаты дисперсионного анализа, представленные в табл. 3, показали, что у листьев рябины обыкновенной наблюдалась большая асимметрия в ширине листа $\left(j_{1}\right)$ и расстояния между основаниями первой и второй жилок второго порядка $\left(j_{3}\right)$. Для остальных рассматриваемых метрических билатеральных признаков зафиксированы меньшие значения показателей асимметрии. 
Таблица 3

Показатели флуктуирующей асимметрии листьев рябины обыкновенной, произрастающих в условиях урбанизированных территорий Красноярского края

\begin{tabular}{|c|c|c|c|c|c|c|}
\hline \multirow{2}{*}{ 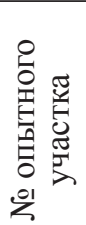 } & \multicolumn{5}{|c|}{$f a_{j}$} & \multirow[b]{2}{*}{$\mathrm{Fa}$} \\
\hline & $j=1$ & $j=2$ & $j=3$ & $j=4$ & $j=5$ & \\
\hline 1 & 0,176 & 0,091 & 0,140 & 0,061 & 0,065 & 0,023 \\
\hline 2 & 0,167 & 0,071 & 0,117 & 0,040 & 0,057 & 0,033 \\
\hline 3 & 0,214 & 0,099 & 0,181 & 0,039 & 0,057 & 0,011 \\
\hline 4 & 0,141 & 0,051 & 0,084 & 0,029 & 0,030 & 0,009 \\
\hline 5 & 0,219 & 0,094 & 0,158 & 0,058 & 0,050 & 0,010 \\
\hline 6 & 0,259 & 0,105 & 0,124 & 0,061 & 0,069 & 0,044 \\
\hline
\end{tabular}

Таблица 4

Факториальные нагрузки на метрические билатеральные признаки листовой пластинки рябины обыкновенной

\begin{tabular}{|c|c|c|c|c|}
\hline \multirow{2}{*}{ Показатели } & $\begin{array}{c}\text { Факторные нагрузки на признаки } \\
\text { до вращения факторов }\end{array}$ & \multicolumn{2}{|c|}{$\begin{array}{c}\text { Факторные нагрузки на признаки } \\
\text { после варимаксного вращения факторов }\end{array}$} \\
\cline { 2 - 5 } & Фактор 1 & Фактор 2 & Фактор 1 & Фактор 2 \\
\hline$j=1$ & $-0,879$ & $-0,076$ & 0,764 & 0,440 \\
\hline$j=2$ & $-0,967$ & $-0,234$ & 0,927 & 0,361 \\
\hline$j=3$ & $-0,630$ & $-0,732$ & 0,936 & $-0,239$ \\
\hline$j=4$ & $-0,837$ & 0,123 & 0,616 & 0,580 \\
\hline$j=5$ & $-0,910$ & 0,237 & 0,610 & 0,715 \\
\hline$F A$ & $-0,530$ & 0,821 & $-0,034$ & 0,977 \\
\hline $\begin{array}{c}\text { Информационные } \\
\text { вклады факторов }\end{array}$ & 3,919 & 1,342 & 3,075 & 2,186 \\
\hline
\end{tabular}

Как известно, развитие листовых пластинок древесных растений в значительной степени определяется условиями их произрастания и, в частности, уровнем оказываемого антропогенного воздействия. Поскольку сбор растительного сырья был осуществлен в ограниченный период времени, а рассматриваемые территории мало отличаются по климатическим характеристикам, любые стрессовые факторы в окружающей природной среде, приводящие к увеличению онтогенетического шума, могут вызывать дестабилизацию морфогенеза листовой пластинки древесных растений [4]. Проведенный нами факторный анализ показал: ведущую роль в полученных различиях интегрального показателя флуктуирующей асимметрии оказывает именно антропогенный фактор (выбросы автотранспорта, алюминиевого завода, добыча угля). С первым фактором (выбросы автотранспорта) наибольшей связью связаны такие показатели, как ширина левой и правой половинок ли- стовой пластинки, расстояние от основания листовой пластинки до конца жилки второго порядка, расстояние между основаниями первой и второй жилок второго порядка. Со вторым фактором (выбросы от алюминиевого завода) наиболее сильно связаны такие показатели, как угол между главной жилкой и второй от основания листа жилкой второго порядка и интегральный показатель флуктуирующей асимметрии (табл. 4).

Выявили, что менее всего подвержены действию факторов: выбросы от автотранспорта, промышленных предприятий опытные участки № 4 (условно фоновый) и № 5 (г. Красноярск, Свердловский район). На участке № 3 (ЗАТО г. Зеленогорск, Красноярский край) наибольшая автотранспортная нагрузка, по сравнению с участками № 1, 5 и 6. На участке № 6 превалирует фактор - выбросы от предприятия, так как сбор образцов проводили в незначительном удалении от предприятия АО «Русал Саяногорский алюминиевый завод») (рис. 2). 


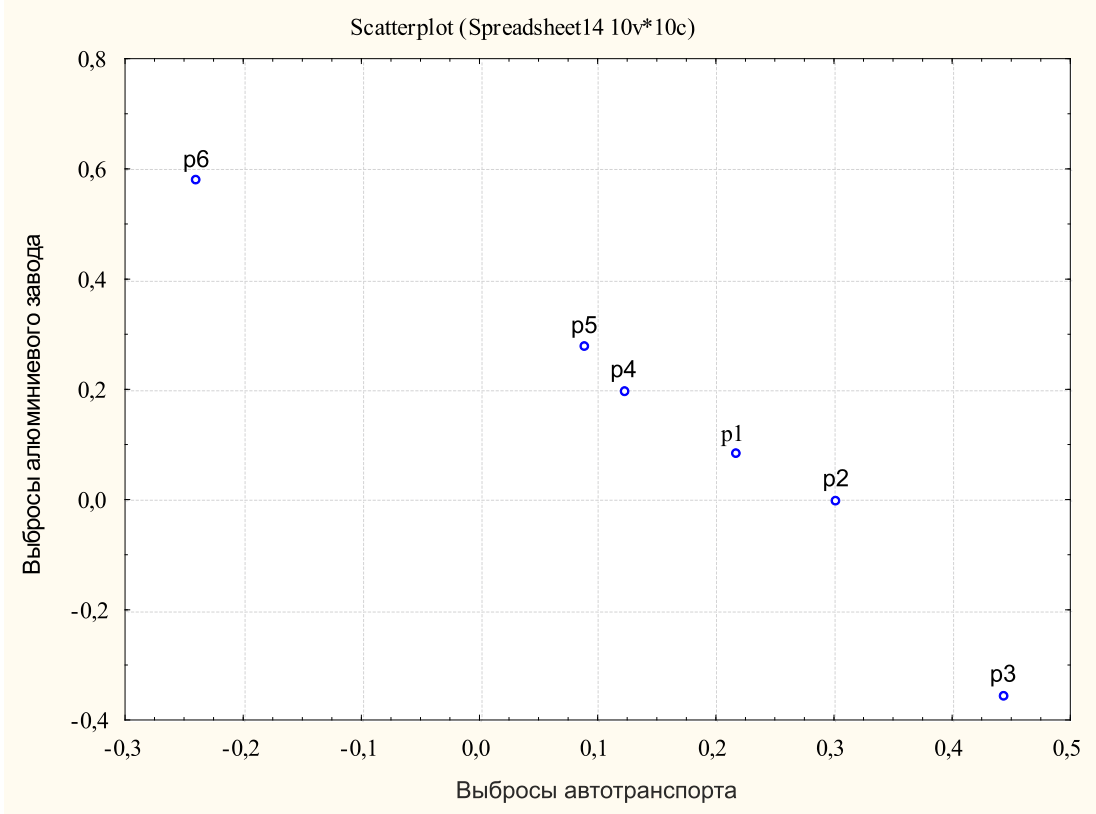

Рис. 2. Проекция изучаемых опытных участков (р1-р6-номера участков в соответствии с табл. 1) на факторные оси (2D) (выполнено в программе Statistica v6.0)

Таблица 5

Сравнительный анализ показателей ФА листьев рябины обыкновенной и листьев березы повислой, произрастающих на территории Свердловского района г. Красноярска

\begin{tabular}{|l|c|c|c|c|c|c|}
\hline \multirow{2}{*}{ Объекты исследования } & \multicolumn{4}{|c|}{$f a_{j}$} & \multirow{2}{*}{$F a$} \\
\cline { 2 - 6 } & $j=1$ & $j=2$ & $j=3$ & $j=4$ & $j=5$ & \\
\hline Рябина обыкновенная & 0,219 & 0,094 & 0,158 & 0,058 & 0,050 & 0,010 \\
\hline Береза повислая [данные согласуются с 12] & 0,113 & 0,381 & 0,268 & 0,563 & 0,074 & 0,047 \\
\hline
\end{tabular}

Ранее отмечалось, что в качестве индикатора состояния окружающей среды может выступать береза повислая [2] вследствие ее высокой чувствительности к действию поллютантов. Сравнительный анализ показателей флуктуирующей асимметрии листовых пластинок березы повислой и рябины обыкновенной (табл. 5) свидетельствует о том, что береза повислая действительно обладает более высокой чувствительностью к неблагоприятным условиям по сравнению с рябиной обыкновенной. Однако такой билатеральный признак, как вариабельность ширины левой и правой половинок листовой пластинки, более выражен у рябины обыкновенной.

Основываясь как на данном признаке, так и на интегральном показателе флуктуирующей асимметрии, можно произвести следующее ранжирование рассматриваемых территорий с точки зрения состояния окружающей среды. Наиболее благоприятные условия для произрастания деревьев зафиксированы в районе Академгородка г. Красноярска (условно фоновый участок), незначительные отклонения - в Свердловском районе города Красноярска и ЗАТО г. Зеленогорск Красноярского края. Сбор растительного сырья в данном случае производился на достаточном удалении от источников антропогенного воздействия. Повышенное значение рассматриваемого показателя $(0,033)$ было обнаружено у растений, произрастающих на небольшом удалении от угольного разреза «Бородинский». Поскольку добыча угля на данном разрезе ведется открытым способом, о чем свидетельствует рисунок (рис. 3), возможно ухудшение экологической обстановки вследствие попадания в атмосферу шахтных газов, а также твердых и газообразных веществ от горящих отвалов. Наибольший интегральный показатель ФА $(0,044)$ выявлен в г. Саяногорске (республика Хакассия) у растений, произрастающих на незначительном удалении от $\mathrm{AO}$ «Русал Саянский алюминиевый завод». 


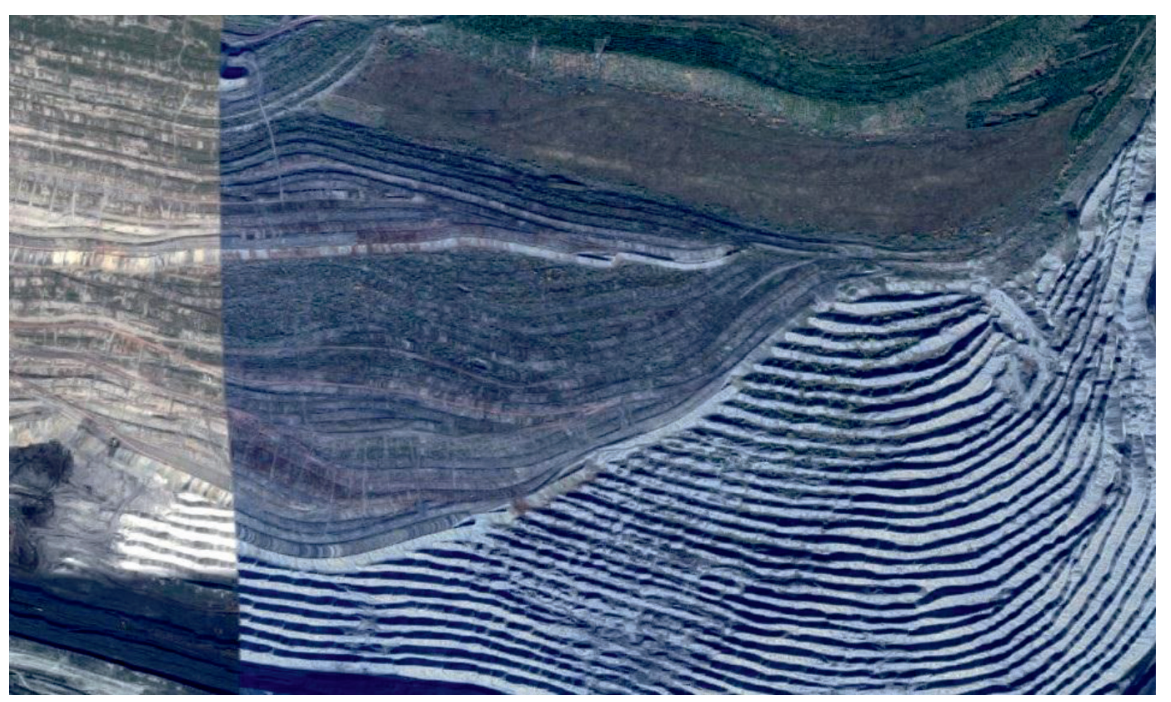

Рис. 3. Открытые карьеры угольного разреза «Бородинский», Красноярский край (скриншот выполнен в приложении Google Kapmы)

В то же время следует отметить, что ранжирование территорий по степени антропогенного воздействия на основании изучения флуктуирующей асимметрии листовых пластинок рябины обыкновенной проводить нецелесообразно в связи с их пониженной чувствительностью по сравнению с березой повислой. Однако можно рассматривать вопросы озеленения как городских территорий, характеризующихся повышенной антропогенной нагрузкой, так и санитарнозащитных зон промышленных предприятий за счет высадки данного дерева.

\section{Выводы}

1. Более чувствительным показателем по сравнению с листовой пластинкой березы повислой при оценке состояния окружающей среды может служить степень варьирования ширины левой и правой половинок листовой пластинки рябины обыкновенной.

2. Сравнительный анализ показателей и интегральных индексов флуктуирующей асимметрии листовых пластинок березы повислой и рябины обыкновенной, произрастающих в Свердловском районе г. Красноярска, выявил разную степень нарушения стабильности развития видов. Вследствие этого возможно озеленение городских территорий, а также территорий вблизи источников антропогенного загрязнения путем высаживания рябины обыкновенной.

\section{Список литературы / References}

1. Гуртяк А.А., Углев В.В. Оценка состояния среды городской территории с использованием березы повислой в качестве биоиндикатора // Известия Томского политехнического университета. 2010. Т. 317. № 1. С. 200-204.

Gurtyak A., Uglev V.V. Assessment of a condition of the environment of the urban area with use of a birch povisly as the bioindicator // Bulletin of the Tomsk Polytechnic University. 2010. V. 317. № 1. P. 200-204 (in Russian).

2. Низкий C.Е., Сергеева А.С. Флуктуирующая асимметрия листьев березы плосколистной в качестве индикатора экологического состояния селитебной территории // Вестник КрасГАУ. 2012. № 5. С. 221-223.

Nizky S.E., Sergeyeva A.S. Fluctuating Asymmetry of the Flat-Leaved Birch Leaves as an Environmental Indicator of a Settlement Territory // Vestnik KrasGAU. 2012. № 5. P. 221223 (in Russian).

3. Хузина Г.Р. Характеристика флуктуирующей асимметрии билатеральных признаков листа липы мелколистной (Tilia cordata L.) // Вестник Удмуртского университета. Cерия: Биология. Науки о земле. 2011. № 3. С. 47-52.

Huzina G.R. Characteristic of the fluctuating asymmetry (FA) of bilateral features for a leaf of a small-leaved Linden (Tilia cordata L.) // Bulletin of the Udmurt university. Biology. Sciences about the earth. 2011. № 3. P. 47-52 (in Russian).

4. Коротченко И.С. Биоиндикация загрязнения районов г. Красноярска по величине флуктуирующей асимметрии листовой пластинки вяза приземистого // Вестник КрасГАУ. 2015. № 11. C. 67-72.

Korotchenko I.S. Bioindication of Pollution of Districts of Krasnoyarsk in Size of the Fluctuating Asymmetry of the Sheet Plate of Siberian Elm // Vestnik KrasGAU. 2015. № 11. P. 67-72 (in Russian).

5. Полонский В.И., Полякова В.С. Сирень венгерская перспективный биоиндикатор для сравнительной оценки степени загрязнения городской среды // Вестник КрасГАУ. 2014. № 2. C. 89-92.

Polonskiy V.I., Polyakova V.S. Hungarian Lilac the Perspective Bioindicator for Comparative Assessment of the Urban Environment Pollution Degree// Vestnik KrasGAU. 2014. №. 2. P. 89-92 (in Russian).

6. Klisaric N.B., Miljkovic D., Avramov S., Zivkovic U. Fluctuating asymmetry in Robinia pseudoacacia leaves - possible in situ biomarker? Environ. Sci. Pollut. Res. 2014. V. 21. № 22. P. 12928-12940. DOI:10.1007/s11356-014-3211-2.

7. Попельницкая И.М., Попов А.О. Флуктуирующая асимметрия листьев тополя бальзамического (Populus bal- 
samifera L.) в городской среде // Успехи современного естествознания. 2017. № 12. С. 72-78.

Popelnitskaya I.M., Popov A.O., Fluctuating asymmetry of poplar (Populus balsamifera) in the urban environment // Advances in current natural sciences. 2017. № 12. P. 72-78 (in Russian).

8. Козлов М.В. Исследование флуктуирующей асимметрии растений в России: мифология и методология // Экология. 2017. № 1. С. 3-12. DOI: 10.7868/S0367059717010103.

Kozlov M.V. Plant studies on fluctuating asymmetry in Russia: Mythology and methodology // Russian Journal of Ecology. 2017. T. 48. № 1. P. 1-9. DOI: 10.1134/S1067413617010106.

9. Захаров В.М., Баранов А.С., Борисов В.И., Валецкий А.В., Кряжева Н.Г., Чистякова Е.К., Чубинишвили А.Т. Здоровье среды: методика оценки. Методическое руководство для заповедников. М.: Центр экологической политики России, 2000. $68 \mathrm{c}$.

Zakharov V.M., Baranov A.S., Borisov V.I., Valetsky A.V. Kryazheva N.G., Chistyakova E.K., Chubinishvili A.T. Health of the environment: assessment technique. The methodical management for reserves. M.: Center for environmental policy of Russia, 2000. 66 p. (in Russian).
10. Методические рекомендации по выполнению оценки качества среды по состоянию живых существ: распоряжение Росэкологии от 16 октября 2003 г. № 460-р. М., 2003. 24 с.

Methodical recommendations about performance of assessment of quality of the environment about a condition of living beings: Rosekologiya's order of October 16, 2003 №. 460-r. M., 2003. 24 p. (in Russian).

11. Зорина A.А. Методы статистического анализа флуктуирующей асимметрии // Принципы экологии. 2012. Т. 1. № 3. C. $24-47$.

Zorina A.A. Methods of statistical analysis of the fluctuating asymmetry // Principles of ecology. 2012. V. 1. № 3. P. 24-47 (in Russian).

12. Первышина Г.Г., Коротченко И.С., Волхонская М.С. Стабильность развития интродуцента - ореха маньчжурского в сравнении с березой повислой в условиях города Красноярска // Вестник КрасГАУ. 2017. № 11. С. 178-185.

Pervyshina G.G., Korotchenko S.I., Volkhonskaya M.S. Developmental stability of introduced species - manchurian nut in comparison with betula pendula in the conditions of the city of Krasnoyarsk // Vestnik KrasGAU. 2017. № 11. P. 178-185 (in Russian). 